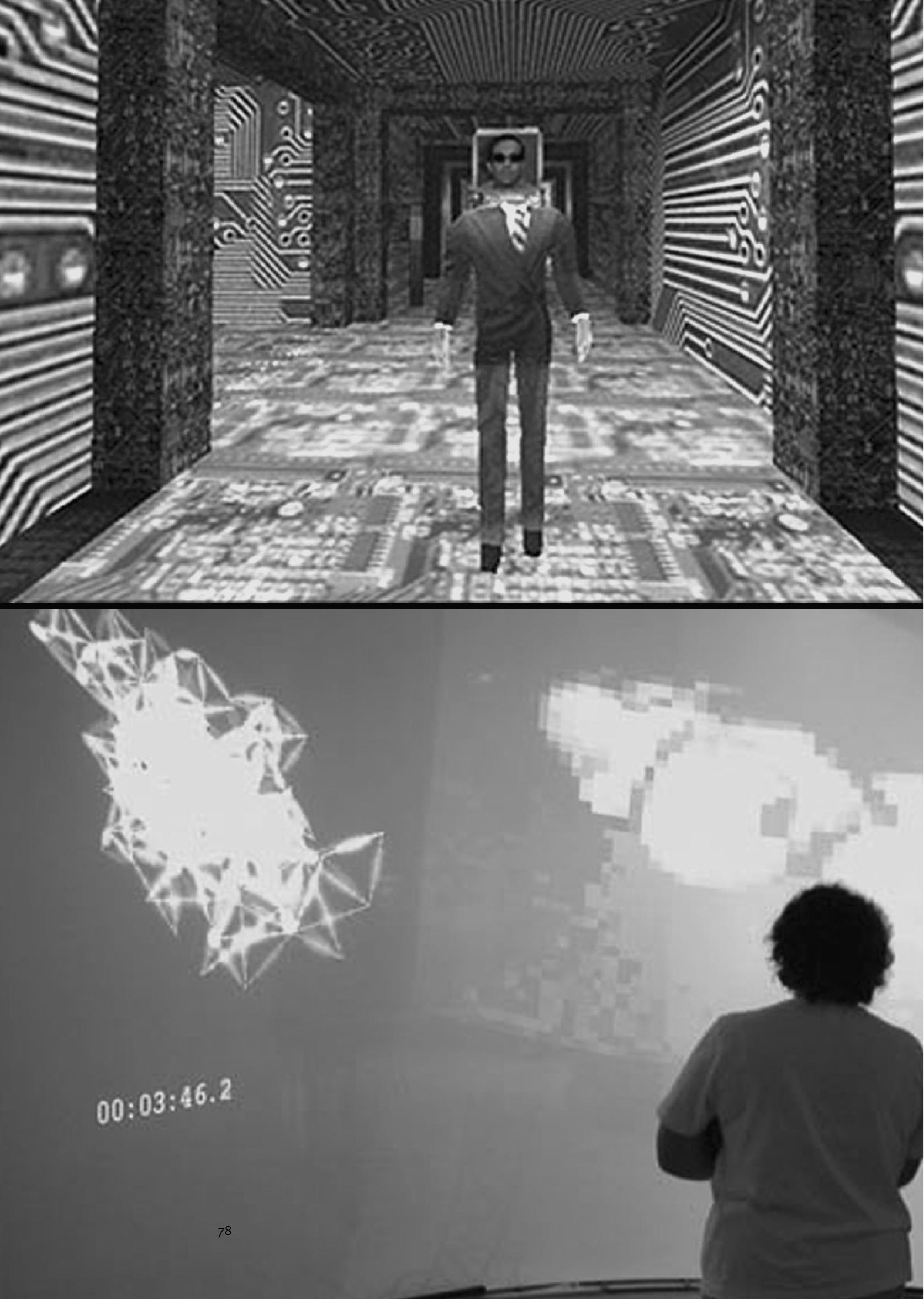


Adriana de Souza

e Silva

\section{ARTE, INTERFACES GRÁFICAS E ESPAÇOS VIRTUAIS}

Este artigo trata de como a arte mediada por tecnologia lida com a conexão entre espaços físicos e digitais. Em vez de analisar a arte midiática contemporânea, na qual a conexão entre o físico e o virtual é aparente, esta análise enfatiza experiências anteriores que combinavam arte, tecnologia, espaços físicos e virtuais. A argumentação divide-se em duas partes. A primeira envolve experiências artísticas com ambientes de multiusuários. A segunda analisa a arte da telepresença, evidenciando que o desejo de conectar indivíduos através de longas distâncias e de misturar o virtual ao físico é mais antigo do que o "ciberespaço".

Palavras-chave:

arte da telepresença, mundos virtuais, interfaces gráficas, espaços virtuais, espaços físicos.

\section{Introdução}

Artistas usam a tecnologia existente para desafiar seus limites, antevendo novos desenvolvimentos para as interfaces em uso. Após o aparecimento das tecnologias digitais, é cada vez mais evidente que artistas indagam sobre a relação entre espaços físicos e virtuais, assim como exploram a mudança de nossa percepção do espaço através do uso de diversas interfaces físicas. Hoje podemos perceber uma hibridização dos espaços físicos e virtuais devida ao uso de tecnologias nômades de comunicação e da computação ubíqua. O uso de sensores, interfaces móveis e de dispositivos miniaturizados embutidos no ambiente torna o espaço digital parte integrante do espaço físico, proporcionando o aparecimento de uma arte híbrida, que conecta espaços anteriormente considerados distintos.

Espaços físicos e virtuais foram freqüentemente encarados como opostos e não coincidentes. Se o ciberespaço, que correspondia à Internet, foi visto durante a maior parte da década de 1990 como o 'espaço virtual' e, portanto, não material, o espaço físico, material e, portanto, considerado 'real', era encarado como seu oposto. Conseqüentemente, atividades desenvolvidas em mundos virtuais aconteciam à parte do mundo físico e, por outro lado, as atividades no mundo "real" não dependiam de ações no virtual. Para se conectar à Internet, era preciso 'parar' no espaço físico e 'entrar' num outro mundo. Essa idéia, vigente na década passada, influenciou o desenvolvimento de ambientes de multiusuários como espaços desconectados do espaço físico. Assim, tais lugares modelavam o mundo físico através de interfaces gráficas que procuravam, na maior parte das vezes, imergir o usuário em um ambiente outro.

No entanto, ao olhar para o passado, para o início de uma época em que se desenvolvia arte com tecnologias de telecomunicação, também conheci- 
1. Uso aqui o termo 'ambientes gráficos de multiusuários', em vez de 'mundos virtuais', como empregado por DODGE \& KITCHIN [Atlas of Cyberspace. Harlow, Inglaterral Nova Iorque: AddisonWesley,2001.] porque mundos virtuais também podem ser experiências singulares e off-line

2. Conferir http://www.cc.gatech. edu/ asb/ para uma lista completa de projetos de Amy Bruckman. Acesso em: 22 nov. 2004. da como arte da telepresença, é possível perceber o desejo de se conectar espaços físicos e virtuais já muito antes do aparecimento de tecnologias nômades de comunicação. O surgimento - e repentina ubiqüidade - da Internet e da realidade virtual freqüentemente escondeu tais tendências, evidenciando a expansão de um mundo virtual, o ciberespaço, desenvolvido fora do espaço físico.

Este artigo comporta duas partes distintas, mas complementares. A primeira concentra-se em experiências artísticas que incluem ambientes gráficos de multiusuários ${ }^{1}$ e na relação entre a arte e os jogos. A segunda parte procura achar na arte o caminho regresso para a conexão entre os espaços físicos e virtuais. Aqui, uma rápida análise do início da arte da telepresença nos ajudará a entender que o desejo de conectar indivíduos através de longas distâncias e de misturar o virtual ao físico é muito mais antigo do que o "ciberespaço".

\section{Arte e mundos virtuais}

Há poucas experiências artísticas que exploram MUDs ou mundos virtuais. Existem muitos exemplos de mundos virtuais comerciais, como AlphaWorld, além de MOOs desenvolvidos por universidades com fins educativos, como os criados por Amy Bruckman no Georgia Tech². Uma das razões para essa lacuna na exploração artística de ambientes de multiusuários está conectada ao fato de que tais espaços são originalmente descendentes de jogos. E jogos não são, normalmente, considerados como arte. Entretanto, a tecnologia de jogos eletrônicos inspirou alguns artistas que tentaram adaptá-la para a criação de experiências estéticas.

A tecnologia de videogames influenciou o desenvolvimento de muitos mundos virtuais, mas apenas alguns foram trazidos para a Internet. Esses mundos virtuais herdaram dos primeiros sistemas de realidade virtual a necessidade de se utilizar um capacete de realidade virtual (HMD) e outras interfaces físicas, tais como a luva de dados. Alguns exemplos artísticos desses ambientes são Osmose (1995) e Ephémère (1998), de Char Davies, e Placeholder (1992), de Brenda Laurel e Rachel Strickland.

\subsection{Quando o jogo encontra a arte}

Apesar de não ser originalmente um ambiente on-line, Imateriais é um exemplo singular de experiência artística com o objetivo de criar um mundo virtual 3D através da tecnologia de jogos. $\mathrm{O}$ ambiente foi idealizado por Jesus de Paula Assis, Ricardo Ribemboim, Celso Favaretto, Ricardo Anderáos e Roberto Moreira para a exposição do Itaú Cultural que aconteceu em São Paulo em 1999. Tal qual outros jogos gráficos de multiusuários na Internet, como EverQuest ou Ultima Online, Imateriais tem um espaço fixo onde o jogo se desenvolve, que é determinado pelo designer do jogo. No entanto, diferentemente dos jogos de aventura, Imateriais levanta questões teóricas como a relação entre o físico, o virtual e a materialidade dentro de um ambiente de 
multiusuários. Além disso, o ambiente conecta os jogos e a arte de um modo inovador. Naquela época, os autores enfatizaram o pioneirismo do uso da tecnologia de videogame para desenvolver um ambiente que não era um jogo, pois prescindia da competição entre jogadores. Durante a exposição, os autores observaram a reclamação constante das crianças em relação à ausência de alvos que pudessem matar, como nos jogos tradicionais. Reclamação semelhante também foi ouvida por Char Davies ao exibir Osmose e Ephémère. De qualquer forma, construir um jogo de extermínio não era o objetivo de Imateriais.

Com a intenção de discutir o atual estado do virtual e sua relação com a materialidade, o Instituto Itaú Cultural desenvolveu uma exposição de arte midiática com o mesmo nome: Imateriais. O objetivo era reeditar Les Immatèriaux, a exposição francesa que ocorrera em 1985, no Centro Georges Pompidou, mas agora em um meio digital. Imateriais é um exemplo de como ambientes de multiusuários foram considerados espaços (virtuais) e como seus autores desafiaram algumas questões fundamentais relacionadas a tais ambientes.

O mundo virtual é um ambiente de multiusuários em 3D que explora a relação entre ver e sentir. Mundos virtuais tridimensionais são espaços visuais, pelos quais os usuários podem se locomover. As principais interfaces utilizadas para a conexão com tais lugares são monitores, teclados, mice e, algumas vezes, capacetes de realidade virtual. Assim, geralmente não há o uso de outros sentidos além da visão. Imateriais desafiou tal pressuposto, ao criar diversas salas interconectadas, cujos temas eram os cinco sentidos: paladar, tato, olfato, audição e visão. O objetivo, de acordo com os autores, era estudar o "impacto de sensações simuladas sobre um corpo simulado"

Para imergir no mundo virtual, o visitante deveria, em primeiro lugar, passear pela exposição, cuja finalidade era estimular os sentidos. Por exemplo, havia uma sala com diversos odores tão diferentes quanto um consultório de dentista ou uma casa limpa. Havia outra sala com pequenas bolinhas comestíveis de sabores estranhos, além de outra sala com orifícios através dos quais o visitante poderia introduzir a mão e sentir o que havia do outro lado. Após toda essa estimulação de sentidos, o visitante finalmente chegava ao ambiente tridimensional.

Antes de entrar no mundo, porém, cada participante deveria tirar uma fotografia de seu rosto, a qual seria usada como a face do avatar. Mais uma vez, questões tradicionais de identidade em mundos virtuais eram provocadas. Os ambientes de multiusuários foram amplamente estudados como espaços de liberdade, principalmente porque não havia a necessidade de se identificar e o usuário poderia escolher tantas identidades quanto quisesse. Em Imateriais, o usuário não podia esconder sua identidade, pois a fotografia proporcionava uma pista óbvia. O contexto da exposição criava uma situação ainda mais irônica, pois era possível estar visitando o show com um amigo (no espaço físico) e, subitamente, encontrá-lo (no espaço virtual). Era possível saber com quem se estava conversando, mas seu rosto não passaria de uma fotografia estática.
3. "Imateriais em meio virtual". CD-ROM Imateriais. São Paulo: Instituto Itaú Cultural, 1999. 
Os participantes do ambiente de multiusuários podiam conversar uns com os outros. O som era também localizado espacialmente, o que significava que, se alguém gritasse, sua voz seria audível mesmo para aqueles que não se encontrassem na mesma sala. Alguns visitantes contaram que, para encontrar alguém no mundo virtual, simplesmente gritavam seu nome e perguntavam: "Fulano, onde está você?”. O cômico dessa situação, no entanto, é que o ambiente criava um duplo sentido de espaço, pois o sujeito sendo procurado no mundo virtual poderia estar bem ao seu lado no mundo físico. Apesar de o avatar possuir uma perspectiva de primeira pessoa, os usuários podiam ver seu reflexo nos diversos espelhos distribuídos pelo ambiente. Tais espelhos também funcionavam como amplificadores e duplicadores do espaço, uma vez que ao aproximar-se de um espelho, tinha-se a sensação de se estar encontrando um outro alguém. Após alguns instantes, descobria-se que a pessoa "do outro lado" era apenas um reflexo de si próprio.

Outra questão importante em Imateriais, de acordo com os autores, era mostrar ao visitante que as bordas entre o material e o imaterial estão mais fluidas, porém evitando "(1) o otimismo de "tecno-utópicos" (o virtual é preferível ao real para as relações humanas [...]; (2) o pessimismo dos neoluditas (o vir-

4. Idem. tual é o fim das relações físicas interpessoais [...]”. O que é mais importante, porém, é que Imateriais procurava levar sensações físicas para o espaço virtual. Numa época em que a maioria dos designers de mundos virtuais estava preocupada apenas com o espaço virtual em si, os autores de Imateriais investigavam possíveis conexões entre o físico e o virtual. O "mundo virtual físico" recebeu mais de doze mil visitantes em um mês e permitia que 25 pessoas pudessem interagir simultaneamente.

A exposição virtual de Imateriais pôde ser visitada na Internet desde a abertura da mostra em São Paulo, em agosto de 1999, até maio de 2000. Na Internet, alguns aspectos do ambiente não puderam ser experimentados de modo completo. O mundo ainda era de multiusuários, incluindo até 32 usuários ao mesmo tempo. No entanto, os habitantes não podiam usar a voz para conversar uns com os outros e apenas podiam escolher avatares predefinidos, como geralmente acontece em mundos virtuais. O corpo do avatar era sempre o mesmo, porém era possível escolher entre uma gama de olhos, narizes, bocas ou mesmo decidir usar a própria fotografia como o rosto do avatar. O Instituto Itaú Cultural também lançou uma versão em CD do mundo, parecida com a versão na Internet, com exceção da característica do ambiente de multiusuários.

Imateriais foi reexibido, em 2001, no Museu da Imagem e do Som em São Paulo. Em 2003, o Itaú Cultural desenvolveu uma nova exposição sobre a história dos jogos eletrônicos, Game o quê?, na qual o mundo 3D era uma das atrações. Apesar de Imateriais não ser um jogo de aventura, os autores foram inspirados pela história dos jogos eletrônicos de ação. O estudo de como as interfaces desses jogos evoluíram ao longo de 30 anos de história facilita a compreensão de como os ambientes de multiusuários se tornaram lugares gráficos. 
Os primeiros videogames invariavelmente incluíam luta, guerra e tiros. Com o desenvolvimento de interfaces gráficas, alguns deles se modificaram para incluir outros temas, como jogos de RPG. No entanto, a forte associação com jogos de ação muitas vezes impediu os jogos de se misturarem com a arte. Considerado o primeiro videogame, Spacewar!, criado em 1961 no MIT, era composto de pontos monocromáticos que simulavam um ambiente de espaço sideral. Além de ser o primeiro jogo eletrônico, era também a primeira simulação computacional a incluir uma representação gráfica. Onze anos mais tarde, em 1972, Pong foi o primeiro videogame com distribuição comercial, podendo ser comprado e jogado em casa. Pong foi inspirado no osciloscópio, um instrumento eletrônico que permite a observação de sinais elétricos em tubos de raios catódicos, como a TV e as telas de computadores. No Brasil, foi comercializado com o nome de Telejogo Philco, em 1974, conta Jesus de Paula Assis $^{5}$. Pong era uma quadra de tênis estilizada. Dois botões controlavam o movimento de duas barras, com as quais o usuário podia amparar uma bola. $\mathrm{O}$ objetivo do jogo era jogar a bola no campo do adversário, esperando que o outro não conseguisse retorná-la. Os videogames continuaram a se desenvolver, até que Pac-Man foi lançando em 1980. Curiosamente, a finalidade do jogo desenvolvido por Moru Iwatani era criar uma experiência diferente da tradicional 'atirar/matar' e um jogo que se parecesse mais com um desenho animado do que com um videogame. Além disso, Pac-Man criou um labirinto como o espaço do jogo, que consistia em uma cabeça ambulante que se movia através desse labirinto, comendo pontos e fugindo dos fantasmas que tentavam impedi-la de explorá-lo. A interface do DOS migrou mais tarde para os sistemas operacionais Windows e Macintosh, sendo encarada como o protótipo do que é hoje entendido como videogame "clássico".

Essa história mudou substancialmente por volta de 1992, quando dois eventos aconteceram simultaneamente: os computadores pessoais se tornaram mais acessíveis e o jogo do atirador em primeira pessoa, Wolfenstein 3D, foi lançado pela ID Software. Esse jogo com interface gráfica tridimensional rapidamente excedeu em popularidade o mais conhecido jogo de DOS daquele tempo, Prince of Persia. Wolfenstein 3D era, originalmente, um jogo de tabuleiro e a versão eletrônica foi modelada de acordo com um labirinto em seis aventuras, cada uma das quais com nove níveis de dificuldade. Nos dois anos seguintes, videogames semelhantes foram criados, como Commander Keen e Ken's Labyrinth.

Em 1994, acontece outro passo importante na história dos jogos de ação. Após o sucesso de Doom, a ID Software lança Doom II. A história é similar à do primeiro Doom: um jogador solitário está de volta à Terra e encontra o planeta infestado de alienígenas extraterrestres. O jogador é, então, compelido a lutar contra os inimigos usando diversos tipos de armas e passando por diferentes níveis de dificuldade. Doom II melhorou a interface de Wolfenstein 3D, incluindo gráficos mais realísticos. As sombras eram mais perfeitas, os jogadores de fato "andavam" em vez de deslizarem pelo chão, e podiam também subir e
5. ASSIS, Jesus de Paula "Uma pequena história dos jogos de ação. Situando a questão de Imateriais". CD Imateriais. 
6. Disponivel em:

http://www.aec.at Acesso em: 22 nov. 2004.

7. Banja também ganhou o EuroPrix 2001 na categoria ficção e histórias narrativas.

descer escadas em prédios com vários andares. Os níveis em Wolfenstein 3D tinham apenas uma camada, o que significa que, apesar de representar um ambiente em três dimensões, era apenas possível se mover em duas direções: esquerda/direita e frente/trás. Não se podia pular ou subir escadas.

No entanto, além de todos os fatores acima mencionados, a inovação mais importante de Doom foi a criação do ambiente de multiusuários. Até quatro jogadores podiam dividir o espaço do jogo através da Internet ou em uma rede local, podendo, então, lutar uns contra os outros ou juntar-se contra monstros que certamente apareceriam. Mais tarde surgiram outros jogos mais avançados graficamente, mas que seguiam o mesmo estilo, como Quake. Todos eles possuíam duas características em comum: a regra "veja e atire” e o espaço labiríntico.

Andar através de labirintos é uma característica comum da história dos jogos em geral e também pertence aos jogos de RPG e MUDs. Por outro lado, a regra "veja e atire" foi abolida dos jogos de RPG desde o início. Apesar de os jogadores poderem, às vezes, lutar uns contra os outros, este não era o principal objetivo do jogo. Seria ingênuo afirmar que os jogos necessariamente "evoluem" de ambientes de ação para espaços sociais. É evidente que a característica de multiusuários transforma o ambiente do jogo em uma experiência mais "social" - em oposição ao ato solitário de jogar. De qualquer forma, esse espaço lúdico de encontros pode ser usado tanto como um ambiente de conversação, como para seguir uma aventura ou mesmo para matar inimigos.

A associação com tiros e matança também contribuiu para a visão dos jogos como incompatíveis com a arte. Por outro lado, o desenvolvimento de jogos computacionais é sempre uma questão de se criar ficção e mundos de fantasia, experiências muito próximas ao trabalho artístico. A edição de 2001 do Prix Ars Electronica ${ }^{6}$ expandiu a categoria 'Internet' em dois grupos distintos: Net Vision e Net Excellence. Ars Electronica é a mais importante competição artística européia e é significante que o prêmio Golden Nica na categoria Net Vision tenha sido dado a $\mathbf{B a n j a}^{7}$, um jogo gráfico de multiusuários online. Além disso, o segundo trabalho indicado nessa categoria foi também um jogo: Phantasy Star Online. Entre as menções honrosas em Net Excellence, é possível também encontrar Austropolis, um jogo on-line de simulação política, Netbabyworld, um jogo para crianças na Internet, e Fudkedcompany, igualmente um jogo on-line programado em HTML (HyperText Markup Language), com um website comum.

Dentre esses cinco tipos de jogos, apenas Phantasy Star Online explora uma interface tridimensional, possuindo algumas semelhanças com jogos tipo "veja e mate". Banja, Netbabyworld e Austropolis são ambientes sociais com interfaces bidimensionais desenvolvidas em Flash, enquanto Fuckedcompany é um website em HTML com aspectos políticos. Tais jogos se assemelham aos MUDs porque se configuram como ambientes sociais dentro de um mundo de jogos.

Banja é um ambiente desenvolvido pelo grupo francês Team cHmAn, 
no qual o usuário pode acessar jogos, desenhos animados e salas de chat. O jogo é basicamente uma narrativa que acontece em episódios mensais em um lugar chamado Itland. Logo que o usuário entra no ambiente, assume um avatar Rastafari que, junto com uma abelhinha, percorre algumas salas onde encontra diversos jogos on-line, como, por exemplo, dardos. O usuário tem sempre a possibilidade de acessar a pontuação de outros usuários e trocar dicas e experiências em um fórum. Além disso, há um ambiente de chat no qual o usuário pode adicionar novas salas ou participar de salas já existentes. O jogo cria um mundo virtual completamente novo sobre o qual o usuário pode ler notícias ou baixar protetores de tela. Banja é interessante devido à sua aparência de desenho animado e às qualidades narrativas da história, mas está longe do conceito de mundos virtuais imersivos, no que diz respeito à interação com o ambiente e à criação de personagens. Por interação com o ambiente, refirome à sensação de imersão no espaço (que pode ser alcançada com a capacidade de se mover por um espaço 3D e/ou de modificar esse espaço). Da mesma forma, por criação de personagens, refiro-me à possibilidade de inventar seu próprio avatar e aos níveis de "liberdade" que o usuário pode ter entre a escolha de avatares predefinidos ou personagens construídos através de texto.

Também com uma interface de desenho animado, Netbabyworld é um jogo comunitário adaptado para a Internet e construído ao redor de um grupo de personagens que vive na Península Nettown. O conceito do jogo é similar ao de Banja: o usuário pode escolher entre jogar diversos tipos de jogos on-line, como Ninja Girl, Tune Inn, ou Boatrace, baixar gráficos e filmes, ou participar do laboratório de jogos, que inclui os cidadãos de Nettown e outros jogadores da comunidade. Netbabyworld é especificamente desenhado para crianças e é também construído com uma interface bidimensional.

Phantasy Star Online difere dos trabalhos anteriormente mencionados porque é um jogo de RPG on-line de multiusuários tridimensional. O jogo é modelado como um MUD de Aventura tradicional, no qual os jogadores devem ir para o espaço sideral para colonizar planetas distantes. Os autores do mundo sugerem que seu objetivo era descobrir a melhor maneira de se comunicar e interagir com o outro, criando um jogo on-line baseado na legendária série Phantasy Star de jogos de RPG Sega ${ }^{8}$. Ao entrar no jogo, o jogador podia explorar o mundo digital com, no máximo, quatro outros jogadores na Internet. É notável que o catálogo do Prix Ars Electronica em 2001 apresente Phantasy Star Online como uma tendência em direção à convergência da Internet e do mundo dos jogos. Além disso, os editores sugerem que "o mundo dos jogos está absorvendo os impulsos da Internet: baseando-se em conceitos como colaboração e comunidade, a dimensão dos jogos em rede está, de fato, aumentando assustadoramente". Tal declaração é parcialmente verdadeira. Apesar de a Internet ter certamente ampliado o significado de 'comunidade', permitindo que um grande número de pessoas se encontrasse sem a necessidade de compartilhar a mesma localização geográfica, os jogos de RPG, mesmo fora do mundo digital, já eram baseados em sociabilidade. A novidade, no entanto, é admitir que o mundo dos
8. LEOPOLDSEDER, Hannes \& SCHÖPF, Christine (eds.). Cyberarts 2001. International compendium of the computer arts - Prix Ars Electronica. Vienal Nova Iorque: Springer Verlag, 2001, p. 34.

9. "The gaming world is picking up impulses from the Net: based on concepts of collaboration and community, the dimension of networked playing is, indeed, looming large". Idem, p. 20. 
10. "Phantasy Star Online is particularly striking because of its luminous, other-worldly graphical surface, utilizing themes from high tech, science fiction and fantasy worlds, where entertainment merges into art". Idem, ibidem.

11. MAEDA. Apud HALL, Peter. "John Maeda at the art directors club". In U\&lc Online (Upper \& lowercase Magazine). ed. 26.1.1. jun./jul. 1999. Disponivel em: http://www.itcfonts.com/ul clarticle.asp? $n C o=A F M T$ Esec $=$ ulc Eissue $=26.1 .1$ Eart=johnmaeda. Acesso em: 22 nov. 2004. jogos pode de fato se misturar ao da arte. "Phantasy Star Online é particularmente admirável devido à sua interface gráfica luminosa, de outros mundos, que alude a temas de tecnologia de ponta, ficção científica e mundos de fantasia, onde o entretenimento se mistura com a arte"10, assinalam os editores.

Mesmo assim, não existem muitas iniciativas que combinam jogos, arte, comunidades, Internet e interfaces tridimensionais. Tal fato ocorre, por um lado, porque interfaces gráficas "mapeiam o jogo", destruindo grande parte da fantasia e da imaginação necessárias para jogar jogos de RPG e construir mundos virtuais. Por outro lado, deve-se ao (não) desenvolvimento da linguagem VRML (Virtual Reality Modeling Language).

\subsection{Explorações artísticas de ambientes de multiusuários on-line}

John Maeda, do Aesthetics and Computational Group, no MIT Media $L a b$, afirmou que os designers estão errados ao pensar que podem fazer o que quiserem com os programas gráficos disponíveis no mercado, estando limitados apenas por suas imaginações. De fato, ele diz, estamos limitados pela imaginação de um outro alguém: o programador ${ }^{11}$. De modo semelhante, na maioria dos mundos 3D, o usuário também está restrito, mas desta vez pela imaginação do designer/artista. Isso não significa que ambientes esteticamente interessantes não possam ser criados. Todavia, o modo de interagir com esses espaços está restrito pela sua representação.

Enquanto a linguagem HTML promove a imersão através de links, a emergência da VRML em 1994 possibilitou a modelagem de objetos tridimensionais no espaço virtual, transferindo o elemento imersivo dos links para o eixo Z. O processo de 'leitura' hipertextual, então, transformou-se na ação de 'andar' por espaços digitais e a profundidade começou a ser visualizada através da perspectiva. A VRML também possibilitou o compartilhamento de espaços digitais de uma nova forma, pois os usuários podiam, a partir de então, realmente 'ver' as representações gráficas uns dos outros.

O problema começou quando artistas e designers começaram a construir interfaces que pudessem promover encontros virtuais e transformar o ambiente digital em um local agradável. Como cumprir a tarefa sem literalmente espelhar a cidade física e seus cidadãos? E como criar interfaces gráficas que não eliminassem o caráter imaginativo dos mundos virtuais?

As interfaces gráficas tridimensionais possuem algumas características peculiares relacionadas à representação de ambientes virtuais em rede. Em primeiro lugar, elas criam um espaço desdobrado, permitindo ao usuário uma visão global do ambiente virtual. Tal atributo é um tanto paradoxal, se pensarmos que a WWW cresceu baseada em uma estrutura hipertextual que representa uma visão fragmentada do espaço, como um mapa dobrado do qual não podemos ver além das dobras (ou do link). Além do mais, ao habitar um dos nós da rede, é somente possível visualizar outros nós, mas nunca as bordas. É, portanto, impossível se traçar um mapa. 
Durante o reinado do ciberespaço, na década de 1990, acreditava-se que a integração com o ambiente seria reforçada com a adição de uma outra dimensão às duas da tela, criando um ambiente tridimensional. De acordo com Dodge e Kitchin, os mundos gráficos "são talvez a forma mais próxima de interação on-line dos mundos compartilhados e imersivos de realidade virtual imaginados por escritores ciberpunks" ${ }^{12}$. A principal diferença desses ambientes para os ambientes bidimensionais é que a profundidade não é apenas sugerida, mas visível.

Uma das razões para a quase total ausência de ambientes artísticos de multiusuários está relacionada ao tempo requerido para se participar em tais ambientes. "Criar uma comunidade" não significa apenas desenhar o espaço; também não significa desenhar seus habitantes. Interfaces devem ser desenhadas para representar comunidades já existentes (como as visualizações de listas de discussão e Usenet propostas por Judith Donath ${ }^{13}$ ), ou então deve haver uma forte razão para os usuários se encontrarem (como jogar um jogo, ou construir um lugar). Mesmo assim, participar de uma comunidade virtual demanda muito tempo. Sherry Turkle ${ }^{14}$ já demonstrou esse fato escrevendo sobre indivíduos que passavam mais tempo nessas comunidades virtuais do que fora delas.

Preocupada com o tempo gasto em mundos virtuais e com a progressiva ausência de tempo no mundo contemporâneo, em 2001 a artista midiática Victoria Vesna criou nOtime, uma comunidade virtual dedicada ao tempo que nenhum de nós tem. Vesna começou a perceber que dispomos de cada vez menos tempo em nossas vidas diárias, principalmente devido ao desenvolvimento de várias tarefas ao mesmo tempo (multitasking), ação possibilitada pelas novas tecnologias. A conexão constante e o desaparecimento das fronteiras entre as vidas profissional e pessoal, em vez de criarem a prometida flexibilidade de compromissos e de nos fazer "ganhar" tempo, funcionam exatamente ao contrário do esperado.

Em nOtime, o usuário cria um corpo virtual em poucos passos, mas, obviamente, não tem tempo para dar atenção a esse corpo. $\mathrm{O}$ corpo, então, cresce espontaneamente na Internet e, quando atinge um tamanho determinado, explode, começando novamente. Um outro aspecto interessante do projeto é explorar o conceito do que significa um 'corpo virtual'. O trabalho anterior de Vesna, Bodies Inc., convidava o usuário a criar um corpo on-line em VRML, constituído de uma combinação de diferentes tipos de cabeças, torsos, braços e pernas, com texturas, tamanhos, sexo e sons personalizados. Era um avatar que se parecia com um ser humano. nOtime desconstrói esse avatar antropomórfico em um tetraedro composto por conceitos e intervalos. A idéia por trás do novo corpo virtual é a mesma que também suporta a construção de espaços virtuais: por que imitar o corpo físico, se o corpo virtual pode assumir qualquer forma?

Além disso, nOtime não era apenas uma "comunidade virtual"; o trabalho foi mostrado como uma instalação física em diversos lugares, incluindo o Instituto de Arte de São Francisco, o Museu de Arte de Oklahoma e o Colégio de Atlanta de Arte e Design. A instalação explorava a interação entre espaços
12. "Are perhaps the closest form of online interaction to the shared, immersive VR worlds envisaged by cyberpunk writers". Op. cit., p. 195.

13. Loom. Disponivel em: http://web.media.mit.edu/ $\sim$ karahal/loom/. Acesso em: 22 nov. 2004.

14. TURKLE, S. Life on the screen - Identity in the age of the Internet. Nova Iorque: Simon \& Schuster, 1995. 
físicos e digitais ao permitir que os visitantes nos museus influenciassem e modificassem os corpos virtuais. Os visitantes que andavam pela instalação provocavam a réplica dos intervalos do corpo. Conceitos, então, poderiam ser adicionados ao corpo, mas apenas por aqueles convidados pelo dono do corpo. Os convites poderiam ser feitos via e-mail e os conceitos poderiam ser adicionados on-line ou no próprio local da instalação.

Ambientes artísticos de multiusuários, como Imateriais e nOtime, exploram o físico e o virtual de um modo que não foi prioridade em representações de mundos virtuais durante a década de 1990. Em uma visão superficial, parece que a interconexão entre os espaços físicos e digitais, proporcionada pelo uso de tecnologias nômades de comunicação e da computação ubíqua, é novidade. A Internet fixa tornou-se tão presente em nossa sociedade que há quase uma amnésia cultural em relação à arte das telecomunicações que precedeu a WWW e que já explorava tais questões. No entanto, existem diversas experiências artísticas que abordam a relação entre o físico e o virtual utilizando tecnologias de telecomunicação, como satélites e câmeras de vídeo, desde o início dos anos 70. A maioria desses trabalhos, que geralmente incluíam performances e redes sociais com o objetivo de mostrar que as distâncias geográficas poderiam ser abolidas por meio da tecnologia, antecipou as interações que posteriormente aconteceriam na WWW. A principal diferença entre as explorações artísticas de comunicação na Internet e os trabalhos de telepresença se deve ao fato de que as primeiras necessariamente aconteciam no "ciberespaço", enquanto que as últimas ocorriam em espaços físicos. Em todos esses trabalhos, a idéia era tornar o distante próximo, além de interagir com entidades ausentes "como se elas estivessem aqui". O objetivo da telepresença é criar uma rede comunicacional que pode ser considerada 'virtual' porque não acontece em nenhum lugar específico, "entre” o aqui e o lá.

\section{Telepresença e espaços virtuais}

Artistas como Kit Galloway e Sherrie Rabinowitz, Douglas Davis, Keith Sonnier e Roy Ascott, entre outros, são considerados pioneiros na exploração da arte da telepresença. Lars Rosenberg, no periódico Telepresença, define o termo em contraste à realidade virtual: "Muito semelhante à realidade

15. "Very similar to virtual reality, in which we strive to achieve the illusion of presence within a computer simulation, telepresence strives to achieve the illusion of presence at a remote location". ROSENBERG. Apud WILSON, Stephen. Information arts: intersections of art, science, and technology.

Chapter 6: Telecommunications. Cambridge: MIT Press, 2002, p. 527. virtual, através da qual buscamos alcançar a ilusão de presença dentro de uma simulação computacional, a telepresença procura alcançar a ilusão de presença em uma localidade distante" ${ }^{15}$. Nesse sentido, telepresença é a habilidade de se modificar a percepção do espaço: não o espaço virtual longínquo, mas o espaço físico que se habita.

É possível distinguir a telepresença de seus correlatos telemática e telerrobótica, argumentando que a telepresença utiliza tecnologias de telecomunicação em geral, como telefones, satélites ou videofones, para alcançar a sensação de presença à distância. Nesse sentido, o termo 'telepresença' precede as tecnologias digitais e as redes computacionais. A telemática combina a telepre- 
sença com computadores e foi um importante campo de exploração artística após o surgimento da WWW. O termo em si foi cunhado em 1978 e Roy Ascott foi o primeiro teórico a aplicá-lo à arte, em 1979. Finalmente, a telerrobótica combina a telemática às estruturas robóticas, ocorrendo toda vez que se possa estar presente através da incorporação em um robô. Um dos exemplos mais famosos de arte telerrobótica é o Telegarden, de Ken Goldberg (1995), consistindo em uma estrutura robótica que planta sementes e rega plantas em um mini-jardim, manipulável por usuários na Internet.

As tecnologias de telecomunicação já eram exploradas artisticamente na construção de redes sociais, combinando espaços físicos e virtuais, muito antes dos ambientes de multiusuários na Internet. A utopia de se criar "novos mundos" na Internet temporariamente obscureceu tais experimentos, devido à popularidade da rede digital, mas herdou do início da era da telepresença a crença no poder da tecnologia: bastava construir as estruturas da rede para se criar um ambiente social.

\subsection{Experiências artísticas pioneiras usando os telefones como interfaces}

Uma das primeiras tecnologias de telepresença a ser utilizada artisticamente foi o telefone. Considerado um dos primeiros a explorar telepresença, László Moholy-Nagy utilizou o telefone para encomendar pinturas em porcelana. O próprio artista descreve a situação:

"Em 1922, eu encomendei de uma fábrica de sinais por telefone cinco pinturas em porcelana esmaltada. Eu tinha a tabela de cores da fábrica na minha frente e esbocei minhas pinturas em papel (quadriculado). Do outro lado da linha telefônica, o supervisor da fábrica tinha o mesmo tipo de papel, no qual ele desenhava as formas na posição correta em que eu ditava. (Era como jogar xadrez por correspondência). Uma das pinturas foi entregue em três tamanhos diferentes, de forma que eu pudesse estudar a sutileza das diferenças em cores causadas pela ampliação e redução da pintura" ${ }^{16}$.

Eduardo Kac sugere que ninguém sabe ao certo se a história de Moholy-Nagy é verdadeira, pois sua mulher afirmou que, na verdade, ela encomendou as pinturas pessoalmente. No entanto, essa descrição é importante porque evidencia a idéia de que o artista moderno pode estar subjetivamente distante e pessoalmente ausente da obra.

Em 1969, o Museu de Arte Contemporânea de Chicago organizou uma exposição chamada Arte por Telefone que, de certa forma, repetiu o experimento de Moholy-Nagy. Trinta e seis artistas foram convidados a fazer uma ligação telefônica para o museu e dar instruções aos funcionários acerca de sua obra. O museu, então, produziu os trabalhos e os expôs. O teste da possibilidade de criação remota pode ser considerado o primeiro uso do telefone para a produção de arte. Em todo caso, o telefone não foi explorado como um meio criativo nessa exposição, sendo apenas utilizado, na maioria das obras, como
16. MOHOLY-NAGY. Apud KAC, Eduardo. "Aspectos da estética das telecomunicações”. In RECTOR, Mônica \& NEIVA, Eduardo (eds.). Comunicação na Era PósModerna.Petrópolis: Editora Vozes, 1997, p. 175-199. Disponivel em: http://www.ekac.org/ telecomport.html. Acesso em: 12 jan. 2004. 
uma interface remota para a produção de algo que poderia ter sido feito, por exemplo, se o artista fosse ao museu e conversasse com o curador.

18. Disponivel em: http://www.dismbody.dem on.co.uk/home.html. Acesso em: 17 dez. 2003.
$\mathrm{Kac}^{17}$ conta que um dos raros usos criativos da tecnologia foi desenvolvido por Robert Huot. Sua proposta "envolvia potencialmente todos os visitantes do museu e tentava promover encontros inesperados empregando o acaso $e$ o anonimato. Foram selecionadas vinte e seis cidades nos Estados Unidos, cada uma começando com uma letra do alfabeto e, em cada cidade, um homen chamado Arthur. O sobrenome de cada Arthur era o primeiro listado sob a letra inicial da cidade (por exemplo, Arthur Bacon em Baltimore). O museu expôs uma lista com as respectivas cidades e nomes, e convidava os visitantes a telefonarem e perguntarem por 'Art' (em inglês, a palavra 'art' é, ao mesmo tempo, arte e o apelido de Arthur). A obra era a inesperada conversa telefônica entre o visitante e 'Art', $e$ seu desenrolar dependia exclusivamente dos participantes."

Em suma, o trabalho de Huot apresentava o artista como criador e como contexto, não sendo uma experiência passiva para o visitante. Aqui, o telefone é usado para a transformação do processo artístico em uma experiência social.

Trabalhos mais recentes que utilizam o telefone incluem as obras desenvolvidas pelo Disembodied Art Gallery ${ }^{18}$, um grupo britânico que explora a arte conceitual e da telecomunicação. Por exemplo, Babble era uma instalação de arte telemática criada em 1993 que recebeu mais de 70 contribuições de voz provenientes dos Estados Unidos, Austrália, Japão e Europa. Para participar, era só telefonar para um número na Grã-Bretanha e, então, recitar poesias, ou contar histórias para uma secretária eletrônica. Depois, essas mensagens eram coletadas e tocadas automaticamente para os visitantes de uma galeria de arte em Brighton, toda vez que uma pessoa entrasse na instalação. Temporary Line (1993/4), outra obra do Disembodied Art Gallery, era uma escultura telefônica áudio-reativa. A obra era ativada sempre que um transeunte passasse perto da escultura. Ao ser ativada, o som de vozes sussurrantes percorria a escultura, de aparelho telefônico em aparelho telefônico, randomicamente ao redor dos pés do visitante.

O conceito por trás da maioria desses projetos artísticos não é tanto explorar a comunicação sincrônica, como é considerado o uso comum do telefone, mas investigar as conseqüências da presença gravada ou da voz como uma presença passada. Telefones foram considerados o meio virtual por excelência, pois eliminaram a distância entre vozes descorporificadas. Assim, trasformaram o puro elemento da voz em presença: uma presença ausente. Os artistas citados anteriormente usaram essa tecnologia de telecomunicação para enfatizar não somente essa ausência do espaço, mas também uma ausência do tempo, ao trazer vozes passadas gravadas para dentro do presente imediato.

Heath Bunting, um colaborador do Disembodied Art Gallery, criou uma obra que incorporava o uso da Internet com o objetivo de alcançar uma audiência mais distribuída. No trabalho criado em 1994, intitulado Kings Cross Phone-in, o artista distribuía os números de telefone de quiosques ao 
redor da estação de trem britânica Kings Cross pela Internet e pedia a qualquer um que os achasse para escolher um número, ligar em um horário específico e conversar com quem atendesse ao telefone. De modo semelhante, em dezembro de 1996, StallPlaat criou The Answering Machine Solution C.D., uma ampla coleção de faixas de 30 segundos que poderiam ser usadas como mensagens de secretárias eletrônicas para celebrar o lançamento de seu centésimo CD. Keith de Mendonça, do Disembodied Art Gallery, criou a capa do CD e uma mensagem para inclusão em sua "trilha-sonora".

Também usando telefones em espaços públicos, Stephen Wilson desenvolveu um projeto artístico que utilizava o telefone, chamado Is Anyone There? (1992), que durou uma semana, em São Francisco (EUA). No projeto, cinco telefones públicos, conectados a um sistema computacional capaz de sintetizar a voz humana, tocavam nas ruas a cada hora, com o objetivo de envolver qualquer um que atendesse ao telefone em uma conversa sobre a vida na cidade. O sistema utilizava um programa interativo inteligente de modo a desenvolver com os transeuntes um rápido diálogo. As conversas eram, então, digitalizadas, gravadas e acessíveis posteriormente através de uma instalação que incluía um banco de dados das chamadas. Na galeria, a instalação mudava sem aviso prévio para um sistema que funcionava em tempo-real, telefonando aleatoriamente para telefones públicos de modo a conectar os visitantes do museu com uma pessoa real nas ruas. Com este trabalho, Wilson procurava explorar a comunicação aleatória entre indivíduos desconhecidos, que não ocupavam o mesmo espaço físico, enfatizando o usuário como criador de conteúdo. Além disso, o artista explorava possíveis desenvolvimentos para sistemas de inteligência artificial, através da análise do discurso entre computadores e humanos.

O desenvolvimento dos videofones procurou combinar a comunicação bilateral instantânea, que pertencia ao telefone, com as imagens utilizadas pela TV. A falha dos videofones, contudo, está paradoxalmente conectada ao que era considerado sua maior vantagem: o emprego de imagens. Gilbertto Prado ${ }^{19}$ sugere que os videofones não foram integrados à vida cotidiana porque requeriam muita preparação estética por parte do usuário. Porque o aparelho não transmitia apenas a voz, mas era também capaz de enviar imagens, usuários se preocupavam demais com sua aparência ao telefone. A preocupação estética não era restrita apenas ao interlocutor, mas influenciava também a preparação do ambiente ao redor do aparelho: salas especialmente decoradas foram criadas para acomodar o videofone e impedir que o usuário fosse tomado de surpresa por uma ligação inesperada. Prado também sugere que a Internet legitimou essa desejada distância do sujeito físico, ao representar os usuários através de avatares, fazendo com que os participantes de chats, por exemplo, se sentissem mais à vontade ao lidar com desconhecidos, sem a necessidade de se identificar. Hoje, esse paradigma muda. Há um aumento do número de webcams em chats na Internet, além do aparecimento de telefones celulares equipados com câmeras que permitem o envio instantâneo de fotografias e vídeos. Será que a familiaridade com esse tipo de tecnologia transformará a relação entre a comu- 
nicação interpessoal e a transmissão de imagens?

Enquanto a exploração do telefone como meio de formação de ambiente de multiusuários foi lenta e gradual, outros meios de telepresença, como os satélites e vídeo, foram, desde o início, utilizados artisticamente como forma de comunicação coletiva. Desde a década de 1970, artistas começaram a explorar a transmissão em tempo-real de imagens através de satélites e vídeo como meios de telepresença. Tais obras podem ser encaradas como as primeiras tentativas de criação de um espaço híbrido, que conecta o físico ao virtual através de movimento e comunicação.

\subsection{Vídeo, satélites e telepresença}

O ano de 1977 foi crucial para a arte da telepresença. Foi quando a

20. Disponivel em: http://www.eai.org/eai/ tape.jsp?itemID $=2723$. Acesso em: 17 dez. 2003.

21. Disponível em: http://www.banquete.org. Acesso em: 22 nov. 2004.

22. Zentrum Für Kunst und Medientechnologie (Centro de Arte e Tecnologias Midiáticas).

23. Disponível em: http://www.ecafe.com/ getty/SA/index.html. Acesso em: 22 nov. 2004.

24. "A space with no geographical boundaries". Idem.

25. Disponivel em: http://www.ecafe.com/ getty/HIS/index.html. Acesso em: 22 nov. 2004.
Documenta $6^{20}$, uma exposição de arte ocorrida em Kassel, na Alemanha, mostrou a primeira transmissão ao vivo via satélite feita por artistas. Performances de Nam June Paik, Joseph Beuys e Douglas Davis foram transmitidas para mais de 25 países. Paik e Beuys transmitiram de Kassel, mas Douglas Davis fez sua performance de Caracas, na Venezuela. O trabalho The Last Nine Minutes, reeditado para a exposição Banquete ${ }^{21}$, no $\mathrm{ZKM}^{22}$, em Karlsruhe (Alemanha, 2003), lidava com parâmetros de comunicação midiática e com a idéia da telepresença que explorava o conceito de 'distância'. No mesmo ano, uma colaboração entre os artistas Keith Sonnier e Liza Bear, em Nova Iorque e São Francisco, resultou em Send/Receive Satellite Network: Phase II, uma transmissão via satélite bilateral durante quinze horas entre as duas cidades.

Também em 1977, Kit Galloway e Sherrie Rabinowitz organizaram um espetáculo de dança interativo via satélite envolvendo dançarinos nas costas leste e oeste dos Estados Unidos. Satellite Arts Project ${ }^{23}$ era, de acordo com os autores, "um espaço sem fronteiras geográficas" ${ }^{24}$. Com esse trabalho, os artistas começaram a definir o conceito da 'imagem como um lugar', demonstrando, pela primeira vez, que vários artistas performáticos poderiam aparecer e trabalhar em conjunto, na mesma imagem, mesmo estando em espaços físicos distintos. A partir de tais iniciativas, é possível perceber que o desejo (concretizado) de encontrar indivíduos no mesmo lugar "virtual" é mais antigo do que a experiência da rede digital.

Três anos mais tarde, em 1980, os mesmos artistas desenvolveram Hole in Space ${ }^{25}$, também utilizando satélites. Uma tela de projeção aproximadamente do tamanho de um ser humano foi colocada em Nova Iorque e uma outra, localizada em Los Angeles, ambas no meio da rua. A tela de Nova Iorque mostrava Los Angeles e a de Los Angeles mostrava Nova Iorque, funcionando como "janelas" ou "buracos" para a cidade oposta. O vídeo de documentação do trabalho é extremamente interessante, mostrando os transeuntes simultaneamente admirados e incrédulos em relação às telas. Na época, nenhuma explicação ou crédito foi colocado por perto da obra e muitos cidadãos de fato pen- 
saram que o que estavam vendo era uma imagem gravada. A maioria não acreditava que poderia ver a outra cidade em tempo-real. Por outro lado, os indivíduos começaram a perceber que a instalação poderia ser uma poderosa ferramenta de comunicação em tempo-real entre as duas cidades. No vídeo de documentação, é possível observar pessoas acenando umas às outras, marcando encontros e realmente desenvolvendo uma "rede através do espaço virtual criado por satélites" ${ }^{26}$. No final, o trabalho revelou-se um forte aparelho de comunicação entre as duas cidades, transformando a percepção do espaço físico pelo qual os cidadãos estavam acostumados a passar todos os dias. A adição de uma nova "camada de espaço" mudou as características do espaço público em ambas as cidades durante três dias, transformando o espaço de circulação da rua em um lugar de encontro e comunicação.

Galloway e Rabinowitz procuravam criar redes móveis ao desenvolver a arte da telecomunicação. Com Satellite Arts Project e Hole in Space, os artistas procuravam conectar indivíduos através de longas distâncias usando tecnologias de telecomunicação. Hole in Space, por exemplo, criava um espaço virtual no qual a comunicação ocorria. No entanto, diferentemente dos chats na Internet ou de ambientes de multiusuários, as intervenções de Galloway e Rabinowitz aconteciam em espaços públicos. Ao colocar uma tela em Los Angeles e a outra em Nova Iorque, transeuntes poderiam se encontrar nas ruas para ver e contatar outras pessoas do outro lado da tela. Nesse caso, o "outro lado da tela" não era um ambiente virtual simulado, mas sim uma outra cidade, um espaço físico. Mesmo não compartilhando o mesmo espaço físico contíguo, os participantes da obra se comunicavam em espaços urbanos, influenciando diretamente todos os outros transeuntes. Galloway e Rabinowitz alegam que sempre estiveram interessados em criar um contexto comunicacional que conectasse espaços físicos, em vez de criar um ambiente simulado no qual a comunicação poderia ocorrer, como é o caso da Internet ${ }^{27}$.

No final dos anos 80, os artistas também experimentaram com mundos virtuais em $3 \mathrm{D}^{28}$, mas, de acordo com eles, nada é mais poderoso do que conectar pessoas em espaços físicos. Por não estarem compatilhando o mesmo espaço contíguo, os participantes de Hole in Space criavam um ambiente comunicacional misto, que combinava espaços físicos e um não-lugar virtual onde a troca comunicacional ocorria. Assim, Hole in Space é significativo, entre outros motivos, porque previu, há mais de 20 anos, o poder da comunicação mediada em espaços públicos.

Outro importante projeto do início dos anos 90 foi Telematic Dreaming, de Paul Sermon. Em 1992, o artista criou uma "cama virtual" que poderia ser compartilhada por indivíduos que não se encontravam no mesmo espaço físico. Na verdade, havia duas camas e a imagem da pessoa ausente projetada na cama presente. Telematic Dreaming usava uma rede digital telefônica ISDN para conectar interfaces separadas, que funcionavam como um sistema de videoconferência. Uma das camas estava localizada em um espaço escuro e a outra, em um ambiente iluminado. A cama no claro possuía uma
26. "Network through the virtual space created by the satellites". Idem.

27. Em conversa no the Electronic Café em Santa Monica, Los Angeles (15 nov. 2003).

28. O Electronic Café virtual foi um dos primeiros "lugares" no ambiente de multiusuários Alpha Worlds. 
29. SERMON. Disponível em: http://www.hgbleipzig.de/ $\sim$ sermon/dream/. Acesso em: 22 nov. 2004. "The ability to exist outside of the users own space and time is created by an alarmingly real sense of touch that is enhanced by the context of the bed and caused by an acute shift of senses in the telematic space."

30. DINKLA, Söke. "The history of the interface in interactive art". In

ISEA'94 Proceedings. Helsinki, 1994. Disponivel em:

http://www.maryflanagan.com/courses/2002/we b/HistoryofInterface.html. Acesso em: 08 jun. 2003. câmera situada bem em cima dela, que enviava ao vivo a imagem de vídeo da pessoa que estava deitada através da rede e a projetava na cama que estava no escuro. Ainda havia uma segunda câmera no quarto escuro, que capturava a imagem virtual das duas pessoas na cama e a enviava para uma série de monitores que circundavam a instalação. Ao se olhar para as TVs, parecia que as duas pessoas estavam, na verdade, compartilhando o mesmo espaço. De acordo com Sermon, "a possibilidade de existir fora do próprio espaço e tempo do usuário é criada por um perturbador sentimento de contato físico que é ampliado pelo contexto da cama e causado por uma brusca mudança dos sentidos no espaço telemático" ${ }^{29}$.

No ano seguinte, Sermon substituiu a cama por um sofá, criando Telematic Vision. A tecnologia empregada era a mesma, mas agora, em vez de dividir uma cama, os participantes compartilhavam uma sala de estar. Um participante sentava em um sofá em frente a uma TV, que mostrava a imagem do sofá no qual o participante estava sentado, mas com mais uma pessoa sentada. Esse outro alguém era um participante remoto, sentado em um sofá distante, cuja imagem era transmitida via rede telefônica. Essa pessoa acabava ocupando a mesma sala e assistindo à mesma imagem duplicada na TV.

A maioria dos projetos de telepresença utilizando vídeo e satélites se diferencia de projetos que empregam aparelhos telefônicos devido à transparência da interface. Na arte com telefone, a interface 'telefone' é completamente visível e, algumas vezes, é o sentido final da obra, como no caso de trabalhos explorando toques telefônicos e telefones públicos. Por outro lado, o vídeo e os satélites são majoritariamente usados para a transmissão de imagens, as quais, tomando a atenção dos espectadores, escondem a interface. Tanto em Hole in Space quanto em Telematic Dreaming, os participantes não estavam preocupados, em um primeiro momento, com o tipo de tecnologia que estava sendo utilizada para projetar as imagens. Os efeitos de uma janela nova-iorquina em uma rua de Los Angeles, ou de uma pessoa virtual em sua cama eram mais fortes do que a tecnologia, escondendo o que estava "por trás da imagem".

Considerando o estado da interface no início dos anos 80, Söke Dinkla $^{30}$ observa que a situação poderia ser caracterizada pela expressão: "Participação x Interação". Dinkla define ambientes participatórios como instalações físicas desenvolvidas dentro de ambientes reativos, os quais são basicamente espaços delimitados que, através de sensores e de outras interfaces como câmeras de vídeo, são capazes de reagir às ações do usuário. As obras de Paul Sermon são, em sua maioria, ambientes reativos. Outros exemplos são Videoplace (1974), de Myron Krueger, e Very Nervous System (1986/90), de David Rockeby. Por outro lado, ambientes interativos começaram a ser desenvolvidos com o uso de capacetes de realidade virtual, criando uma situação que isolava o usuário em um espaço virtual, pelo qual ele poderia se mover e com o qual poderia interagir. Assim, o termo 'movimento' passou a não significar mais o deslocamento do artista performático pelo espaço, como nos ambientes físico-reativos, mas o movimento da imagem devido à manipulação do joystick ou 
do mouse. Nesse sentido, o movimento do participante foi substituído pelo movimento da imagem.

A Interação foi dominante durante a maior parte dos anos 90, devido ao amplo desenvolvimento dos sistemas de realidade virtual que procuravam remover os usuários do espaço físico e colocá-los dentro de ambientes modelados. No início do século XXI, no entanto, observamos uma volta ao espaço físico. Diferentemente dos ambientes reativos, contudo, nos quais havia uma porção delimitada do espaço na qual o participante podia agir, o aparecimento de tecnologias nômades de comunicação e da computação ubíqua permite o uso de todo o espaço urbano como uma "superfície reativa". É como se o espaço da cidade se tornasse o mapa de si mesmo, um lugar de interação e de contatos à longa distância, mas sem a necessidade de um espaço restrito.

No mundo virtual de Imateriais, um dos objetivos dos seus criadores era mostrar aos visitantes que o virtual estava sendo progressivamente assimilado na vida cotidiana. Isso significava, segundo eles, que "parte cada vez maior dos eventos cotidianos dá-se no mundo virtual" ${ }^{31}$. Quatro anos mais tarde, em 2003, a mesma frase pode ser usada com um sentido oposto: o virtual está progressivamente sendo assimilado pela vida cotidiana porque o virtual se mistura ao físico, incentivando a comunicação e a mobilidade em espaços físicos. Nesse sentido, a arte da telepresença já representava, nas décadas de 1970/80, uma tentativa, encoberta pelo ciberespaço, de conectar esses espaços físicos e virtuais.

Trabalhos artísticos, ambientes de multiusuários e jogos:

Active Worlds Inc. AlphaWorld. Disponivel em: http://activeworlds.com. Acesso: em 22 nov. 2004.

ASSIS, Jesus de Paula \& RIBEMBOIM, Ricardo. Imateriais. Itaú Cultural, 1999. (CD-ROM)

BAER, Ralph H. Pong. 1966/69. Disponivel em:

http://www.pong-story.com/. Acesso em: 22 nov. 2004.

BUNTING, Heath. Kings Cross Phone-in. Disponivel em: http://www.irational.org/cybercafe/xrel.html. Acesso em: 22 nov. 2004.

DAVIES, Char. Ephémère. 1998. Disponivel em:

http://www.immersence.com/. Acesso em: 22 nov. 2003.

Osmose. 1995. Disponivel em:

http://www.immersence.com/. Acesso em: 22 nov. 2004.

DAVIS,Douglas. The Last Nine Minutes.1977. Disponivel em:

http://www.eai.org/eai/artist.jsp?artistID=271. Acesso em: 22 nov. 2004.

Disembodied Art Gallery. Babble. 1993. Disponivel em:

http://www.dismbody.demon.co.uk/home.html. Acesso em: 22 nov. 2004.

. Temporary Line. 1993/94. Disponivel em:

http://www.dismbody.demon.co.uk/home.html. Acesso em: 22 nov. 2004.

DONATH, Judith \& KARAHALIOS, Karrie. Loom. Copyright (CMIT Media Lab. Disponivel em: http://web.media.mit.edu/ kkarahal/loom/. Acesso em: 22 nov. 2003.

ELECTRONIC Arts Inc. Ultima Online. (C) 2003 Electronic Arts Inc. Disponível em:
31. "Imateriais em meio virtual". CD-Rom Imateriais 
http://www.uo.com/. Acesso em: 22 nov. 2004.

EPIC Games. Ken's Labyrinth. 1993. Informação disponivel em: http://advsys.net/ken/klab.htm. Acesso em: 22 nov. 2004.

GALLOWAY, Kit \& RABINOWITZ, Sherrie. Hole in space. 1980. Disponivel em: http://www.ecafe.com/getty/HIS/index.html Acesso em: 22 nov. 2004. Satellite arts project. 1977. Disponivel em: http://www.ecafe.com/getty/SA/index.html Acesso em: 22 nov. 2004.

GOLDBERG, Ken. Telegarden. 1995. Disponivel em: http://telegarden.aec.at/cgi-bin/knapsack/html/info.html. Acesso em: 22 nov. 2004.

ID Software. Commander Keen. 1990. Informação disponivel em: http://www.3drealms.com/keenhistory/. Acesso em: 22 nov. 2004.

. Doom. 1993. Disponivel em: http://www.idsoftware.com/games/doom/doom-final/. Acesso em: 22 nov. 2004. .Doom II. 1994. Disponivel em: http://www.idsoftware.com/games/doom/doom2/. Acesso em: 22 nov. 2004. . Quake. 1996. Disponivel em: http://www.idsoftware.com/games/quake/quake/. Acesso em: 22 nov. 2004. . Wolfenstein 3D. 1992. Disponivel em: http://www.idsoftware.com/games/wolfenstein/wolf3d/. Acesso em: 22 nov. 2004.

IWATANI, Moru. Pac-man. (C) Namco, 1980.

KAPLAN, Philip. Fuckedcompany. 2001. Disponivel em: http://www.fuckedcompany.com/. Acesso em: 22 nov. 2004.

KRUEGER, Myron. Videoplace. 1974.

LAUREL, Brenda \& STRICKLAND, Rachel. Placeholder. 1992. Disponível em: http://www.tauzero.com/Brenda_Laurel/Placeholder/Placeholder.html. Acesso em: 22 nov. 2004.

MECHNER, Jordan. Prince of Persia. 1989. Disponivel em: http://www.prince-of-persia.com/uk_html/introflash.html. Acesso em: 22 nov. 2004.

NAKA, Yuji; Sonic Team \& SEGA. Phantasy star online. 2001. Disponível em: http://www.sega.com/gamesite/pso3card/content.html. Acesso em: 22 nov. 2004.

NETBABY World. Netbabyworld. 2001. Disponivel em: http://www.netbabyworld.com. Acesso em: 22 nov. 2004.

NEUMAYR, Barbara. Austropolis. Endereço original: http://www.austropolis.at.

ROCKEBY, David. Very Nervous System. 1986/90. Disponivel em: http://homepage.mac.com/davidrokeby/vns.html. Acesso em: 22 nov. 2004.

SERMON, Paul. Telematic Dreaming. 1992. Disponivel em: http://www.hgb-leipzig.de/ sermon/dream/. Acesso em: 22 nov. 2004. . Telematic Vision. 1993. Disponivel em: http://www.hgb-leipzig.de/ sermon/vision/. Acesso em: 22 nov. 2004.

SONNIER, Keith \& BEAR, Liza. Send/Receive Satellite Network: Phase II. 1977.

SONY Computer Entertainment America Inc. EverQuest. (C)1999- 2002. Disponível em: http://everquest.station.sony.com/. Acesso em: 22 nov. 2004. 
Spacewar! Disponível em:

http://lcs.www.media.mit.edu/groups/el/projects/spacewar/. Acesso em: 22 nov. 2004.

StaalPlaat. The Answering Machine Solution CD. 1996. Disponivel em:

http://www.dismbody.demon.co.uk/stcd.html. Acesso em: 22 nov. 2004.

TEAM cHmAn. Banja. (C) copyright TEAMcHmAn 1998-2002. Disponível em:

http://www.banja.com Acesso em: 22 nov. 2004.

VESNA, Victoria. n0time. 2001. Disponivel em:

http://notime.arts.ucla.edu/notime3/. Acesso em: 22 nov. 2004.

Bodies Inc. 1998. Disponivel em:

http://bodiesinc.ucla.edu. Acesso em: 22 nov. 2004.

WILSON, Stephen. Is Anyone There? 1992. Disponivel em:

http://userwww.sfsu.edu/ swilson/art/isany/isany.des.html. Acesso em: 22 nov. 2004.

Este artigo é parte da Tese de Doutorado intitulada "Interfaces Móveis de Comunicação e Subjetividade Contemporânea: de ambientes de multiusuários como espaços (virtuais) a espaços (híbridos) como ambientes de multiusuários” defendida na Escola de Comunicação da UFRJ em fevereiro de 2004. A pesquisa para este artigo foi apoiada pela CAPES (Coordenação de Aperfeiçoamento de Pessoal de Nível Superior) e pelo CNPq (Conselho Nacional de Pesquisa).

Adriana de Souza e Silva é Pesquisadora Senior na Universidade da Califórnia, Los Angeles (CRESST). Doutora em Comunicação e Cultura pela Escola de Comunicação da Universidade Federal do Rio de Janeiro. 